\title{
Stabilization of water-in-oil emulsions with complex of silica particles and hexylamine
}

\author{
A. V. Nushtaeva \\ Penza State University of Architecture and Construction, \\ Physics and Chemistry, Penza, Russia \\ nushtaeva.alla@yandex.ru
}

PACS 82.70.Kj, 68.05.-n, 68.08.-p

DOI 10.17586/2220-8054-2015-6-5-726-732

\begin{abstract}
The properties of emulsions stabilized by complexes of silica particles with hexylamine are analyzed. It is shown that water-in-oil emulsions were obtained only if the hexylamine volume fraction was greater than that of the silica (Aerosil) volume fraction in the aqueous phase. So, in the case of water-in-oil emulsions, hexylamine is a completely equivalent co-stabilizer together with silica, rather than just a solid surface modifier. It is assumed that at high concentrations this short-chain surfactant, together with silica, forms hybrid organic-inorganic particles that are attached at the oil/water interface and promotes the formation of oil droplets in the water.
\end{abstract}

Keywords: solid particles, solid-stabilized emulsions, oil-in-water emulsions, hybrid particle.

Received: 23 January 2015

\section{Introduction}

Solid particles have been recently widely applied alone or together with surfactants for the stabilization of emulsions [1-8] and foams [9-13]. Solid-stabilized emulsions and foams differ from classical surfactant-stabilized systems in that they have some specific properties: (1) extremely high stability; (2) specific rheological properties connected with the structure formation at the interface and in the liquid continuous phase. Micrometer-sized hollow clusters (colloidosomes) are obtained from the solid-stabilized drops $[14,15]$. Such emulsions are used as a template for creating nano-microporous materials [16,17].

Solid particles are considered to be the main stabilizers in an surfactant-solids emulsifying complex, while the surfactant is considered to be a co-stabilizer or modifier. It is usually assumed that the role of surfactant is to reduce the hydrophobicity the particle's surface. For example, cationic surfactants are easily adsorbed at the surface of silica, which is negatively charged in the presence of water. As a result, the silica particle's surface is modified by organic molecules orienting with their hydrophobic hydrocarbon radicals out toward the water. As a result, the surface charge decreases and the contact angle $\theta$ increases. The modified solid particles are attached more strongly at the interface, forming a compact protective interlayer.

A short-chain surfactant hexylamine was used together with silica to stabilize emulsions and foams $[8,10-13,18-21]$. Hexylamine adsorption at the silica particle's surface leads to an increase in the contact angle of wetting by water $[12,13]$ and the angle of selective wetting at the oil/water interface $[20,21]$ and hence, to an increase in the stability of emulsions and foams. In the case of emulsions, the growing concentration of hexylamine even leads to a phase inversion which correlates with the contact angle inversion [20,21].

Using hexylamine-silica complex, we obtained extremely stable emulsions of both types: direct (oil-in-water, $\mathrm{O} / \mathrm{W}$ ) and reverse (water-in-oil, W/O) [18, 19]. At higher silica concentrations, the emulsions did not separate, even when sitting for several months [8]. 
The aim of this study was to compare the results of applying short-chain (hexylamine) and long-chain surfactants (cetyltrimethylammonium bromide) as co-stabilizers with solid particles and to clarify the role of hexylamine in stabilizing the complex.

\section{Materials and methods}

\subsection{Materials}

Different types of silica were used as solid stabilizer: 1) fumed silica powder - Aerosil A-200 and A-380 with specific surface area of 200 and $380 \mathrm{~m}^{2} / \mathrm{g}$ respectively; 2) Ludox HS$40-40 \%$ suspension in water with surface area of $220 \mathrm{~m}^{2} / \mathrm{g} ; 3$ ) hydrolytic silica S-3 with the particle radius $230 \mathrm{~nm}$ obtained via the hydrolysis of silicon esters in an alcoholic medium by the Stober method [22].

The surfactants used as a co-stabilizer were hexylamine and cetyltrimethylammonium bromide (CTAB).

Distilled water was used as the aqueous phase for the preparation of suspension of silica and emulsions.

Saturated hydrocarbons (heptane and decane) or diesel fuel were used as the organic phase for emulsion.

\subsection{Preparation and characterization of emulsions}

The emulsions were obtained by shaking the organic and aqueous phases containing silica and surfactant in a test tube. An emulsion was considered to be stable if it did not separate into distinct phases over the course of a day or more.

\subsection{Determination of silica aggregate size}

The silica aggregate size was determined by turbidimetric analysis of a $0.1 \%$ aqueous suspension of silica.

In the case of the turbidimetric method, the optical density $D$ was measured using a photometer at the analytical wavelength $\lambda=590 \mathrm{~nm}$ and a cuvette length $L=3.011 \mathrm{~cm}$ immediately after shaking. The turbidity $\tau$ and characteristic turbidity $[\tau]$ were calculated as follows:

$$
\tau=\frac{2.303 D}{L}, \quad[\tau]=\frac{\tau}{v_{\mathrm{Hex}}} .
$$

A characteristic $\varphi(z)$ [23] was calculated from value $[\tau]$ :

$$
\varphi(z)=\frac{[\tau] \lambda}{\alpha^{2}}
$$

where $\alpha=\frac{3}{4 \pi}\left|\frac{m^{2}-1}{m^{2}+2}\right|$ is a parameter containing ratio $m=n_{\mathrm{d}} / n_{\mathrm{H}_{2} \mathrm{O}}$ of refractive index of dispersed phase $n_{\mathrm{d}}=1.45$ (silica) and medium $n_{\mathrm{H}_{2} \mathrm{O}}=1.333$.

A table in [23] contains pairs of values $\varphi(z)$ and $z$. We found the theoretical value $\varphi(z)_{\text {theor }}$ nearest to the experimentally obtained value $\varphi(z)_{\exp }$ and calculated magnitude $z$ by formula:

$$
z_{\exp }=\frac{\varphi(z)_{\exp } \cdot z_{\text {theor }}}{\varphi(z)_{\text {theor }}}
$$


The average radius of the silica aggregate was equal to:

$$
R=\frac{z \lambda}{8 \pi}
$$

\subsection{Determination of hexylamine droplet size}

The size of hexylamine droplets dispersed in water was determined via a turbidimetric method at hexylamine concentrations ranging from $0.003-0.151 \mathrm{~mol} / \mathrm{L}$.

Optical density $D$ was measured using a photometer at the following values: $\lambda=340 \mathrm{~nm}$ and $L=3.011 \mathrm{~cm}$ immediately after shaking. Characteristic turbidity $[\tau]$, parameters $\varphi(z), z$ and the average droplet radius of hexylamine were calculated by equations (1) - (4). Refractive index for hexylamine was accepted $n_{\mathrm{d}}=1.375$ (as for hexane).

\section{Results and discussion}

It has been found experimentally that amount of short-chain surfactant like hexylamine required to form emulsions (in complex with silica) is large enough compared to amount of long-chain surfactant like CTAB (Table 1). Here, the relative concentration of co-stabilizer $n_{s}$ (mol/g) was calculated as:

$$
n_{\mathrm{s}}=\frac{\mathrm{C}_{\mathrm{s}}}{\mathrm{C}_{\mathrm{SiO}_{2}}}
$$

where $\mathrm{C}_{\mathrm{s}}$ is the initial concentration of surfactant, mol/L; $\mathrm{C}_{\mathrm{SiO}_{2}}$ is silica concentration, $\mathrm{g} / \mathrm{L}$. The volume fraction of oil during the shaking was equal $\varnothing_{\text {oil }}=0.5$ or $\varnothing_{\text {oil }}=0.33$ for the desired formation of direct emulsions and $\varnothing_{\text {oil }}=0.66$ for the desired formation of reverse emulsions.

TABLE 1. Comparison of the relative concentrations of hexylamine and CTAB

\begin{tabular}{|c|c|c|c|}
\hline \multirow[t]{2}{*}{$\begin{array}{c}\text { Type and } \\
\text { concentration of } \\
\text { silica, \% (mass) }\end{array}$} & \multirow[t]{2}{*}{$\begin{array}{c}\text { Type and } \\
\text { volume fraction } \\
\text { of oil }\end{array}$} & \multicolumn{2}{|c|}{$\begin{array}{l}\text { Type and relative concentration } \\
\text { of surfactant } n_{s}, \mathrm{~mol} / \mathrm{g}\end{array}$} \\
\hline & & $\begin{array}{c}\text { Lower boundary } \\
\text { of } \mathrm{O} / \mathrm{W}\end{array}$ & $\begin{array}{c}\text { Lower boundary } \\
\text { of } \mathrm{W} / \mathrm{O}\end{array}$ \\
\hline & & \multicolumn{2}{|c|}{ hexylamine } \\
\hline $1 \%$ erosil-380 & \multirow[t]{3}{*}{ decane, $\varnothing_{\text {oil }}=0.5$} & 0.002 & 0.014 \\
\hline $2 \%$ erosil-380 & & 0.001 & 0.010 \\
\hline \multirow[t]{2}{*}{$3 \%$ erosil-380 } & & $3 \cdot 10^{-4}$ & 0.007 \\
\hline & & \multicolumn{2}{|c|}{ CTAB } \\
\hline $2 \%$ erosil- 200 & $\begin{array}{c}\text { diesel fuel, } \varnothing_{\text {oil }}=0.33 \\
\text { and } \varnothing_{\text {oil }}=0.66\end{array}$ & $5 \cdot 10^{-7}$ & $7 \cdot 10^{-6}$ \\
\hline $2 \%$ Ludox-HS-40 & heptane, $\varnothing_{\text {oil }}=0.5$ & $5 \cdot 10^{-6}$ & - \\
\hline $3 \% \mathrm{~S}-3$ & $\begin{array}{c}\text { heptane, } \varnothing_{\text {oil }}=0.33 \\
\text { and } \varnothing_{\text {oil }}=0.66\end{array}$ & $1 \cdot 10^{-6}$ & $4.6 \cdot 10^{-6}$ \\
\hline
\end{tabular}
required to form $\mathrm{O} / \mathrm{W}$ and $\mathrm{W} / \mathrm{O}$ emulsions 
The emulsions $\mathrm{O} / \mathrm{W}$ and $\mathrm{W} / \mathrm{O}$ had been achieved at relative concentrations of hexylamine which were 3 orders of magnitude higher than the relative concentrations of CTAB because the short-chain hydrophobicizer is required in larger amounts to achieve the definite contact angle value.

For the silica-CTAB complex, the maximum angle $\theta$ was equal to $53^{\circ}$ (the water receding angle) [7] and the $\mathrm{W} / \mathrm{O}$ emulsions could be obtained only if the oil volume fraction was dominant at the CTAB concentration $(1-5) \cdot 10^{-4} \mathrm{~mol} / \mathrm{L}$. At higher concentrations, CTAB itself stabilizes the $\mathrm{O} / \mathrm{W}$ emulsion in competition with solids, moreover $\mathrm{CTAB}$ forms a second adsorption layer which is oriented with hydrophilic groups toward the water and the contact angle again decreases [24]. Therefore, the phase inversion region and even more the $\mathrm{W} / \mathrm{O}$ emulsion instability region were not achieved in the case of CTAB.

As for hexylamine, increasing the concentration to $n_{s}=0.004-0.014 \mathrm{~mol} / \mathrm{g}$ (for $1-5 \%$ silica) caused an inversion of the contact angle (from $\theta<90^{\circ}$ to $\theta>90^{\circ}$ ) [20] and conversion from $\mathrm{O} / \mathrm{W}$ to $\mathrm{W} / \mathrm{O}$ emulsions. Increasing the hexylamine concentration to $n_{s}=0.01-0.02 \mathrm{~mol} / \mathrm{g}$ resulted in a contact angle $\theta$ value that was approximately $180^{\circ}[20]$ and the $\mathrm{W} / \mathrm{O}$ emulsions became instable. Apparently, the second and subsequent adsorption layers of hexylamine on the silica surface are not oriented. This may explain the increasing contact angle to the point of practically complete hydrophobicity and loss of emulsion stability.

If CTAB is highly soluble in water, then hexylamine is poorly soluble. In the case of hexylamine-silica-stabilized emulsions, the aqueous phase is a three-phase system that contains solid particles of silica and liquid droplets of hexylamine.

When hexylamine and silica concentrations were expressed in terms of volume fractions in the aqueous phase (taking into account the density of silica $2.2 \mathrm{~g} / \mathrm{cm}^{3}$ and of hexylamine $0.766 \mathrm{~g} / \mathrm{cm}^{3}$ ), their magnitudes were comparable (Table 2). Moreover, W/O emulsions were formed when the volume fraction of hexylamine $v_{\text {Hex }}$ exceeded the volume fraction of the solids $v_{\mathrm{SiO}_{2}}$.

TABLE 2. The boundaries of the emulsion stability region for complex Aerosilhexylamine at $\varnothing_{\text {oil }}=0.5$ (decane)

\begin{tabular}{|c|c|c|c|}
\hline \multirow{2}{*}{$v_{\mathrm{SiO} 2}, \%(\mathrm{vol})$} & \multicolumn{3}{|c|}{$v_{\mathrm{Hex}}, \%(\mathrm{vol})$} \\
\cline { 2 - 4 } & Lower boundary of O/W & Phase inversion & Upper boundary of W/O \\
\hline 0.5 & 0.26 & $1.32-1.85$ & 2.77 \\
\hline 0.9 & 0.26 & $1.85-2.64$ & 4.62 \\
\hline 1.4 & 0.13 & $1.85-2.64$ & 5.28 \\
\hline 2.3 & 0.07 & $1.85-2.64$ & 6.60 \\
\hline 3.3 & 0.04 & $2.77-3.70$ & 6.60 \\
\hline
\end{tabular}

Therefore, in $\mathrm{W} / \mathrm{O}$ emulsions, hexylamine is a completely equivalent stabilizer together with silica, rather than simply a solid surface modifier.

Note also that in our experiment, a short-lived W/O emulsion was formed at shaking of hexylamine-water system with decane. The life-time of such emulsion was only a few seconds, but it showed a trend: colloidal droplets of hexylamine have the 'ability' to stabilize the W/O emulsion. 
Silica particles with initial sizes of a few nanometers always formed stable aggregates in powder or in water alone [25]. The average radius of Aerosil A-380 aggregates used in experiments with hexylamine was $38 \pm 5 \mathrm{~nm}$.

As hexylamine is almost insoluble in water, so turbidimetric analysis of the hexylaminewater binary system was carried out to determine the size of hexylamine droplets dispersed in water.

There was linear growth of the turbidity of the system from 0.067 to $1.635 \mathrm{~cm}^{-1}$ with increasing concentrations. However, the characteristic turbidity calculation showed that hexylamine droplet radius remained constant $R=45 \pm 8 \mathrm{~nm}$ regardless of the concentration (Fig. 1). The average radius of Aerosil A-380 aggregates, also determined by characteristic turbidity, was $38 \pm 5 \mathrm{~nm}$. Thus, the hexylamine droplet had a similar size to the silica aggregate.

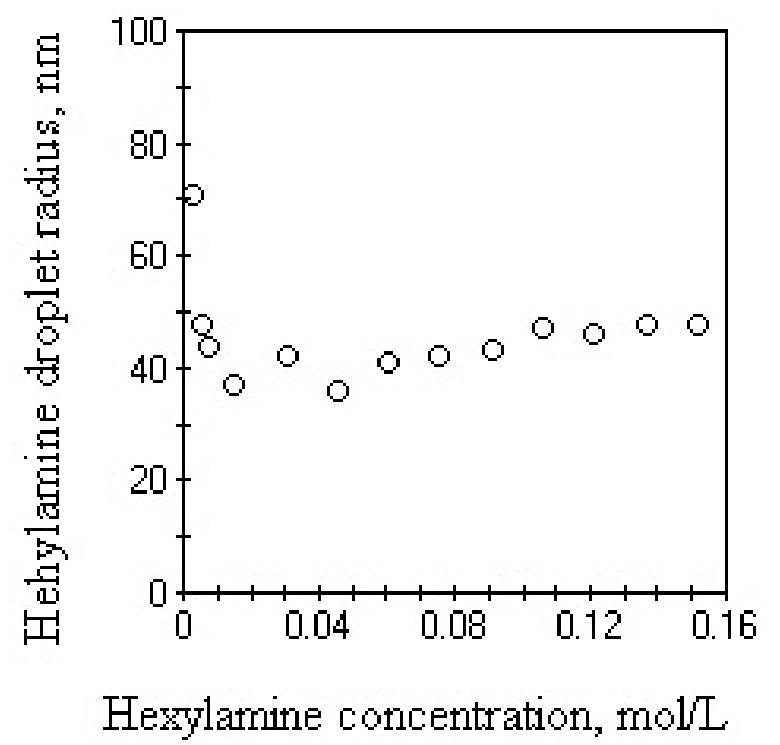

FIG. 1. Radius of hexylamine droplets in hexylamine-water binary system

Thus, the hexylamine-water system is a nanoemulsion. However, this system is not stable, unlike thermodynamically stable nanoemulsions with very low interfacial tension $10^{-2}$ $10^{-5} \mathrm{mN} / \mathrm{m}$ [26]. Hexylamine constitutes a separate a bulk layer which becomes visible at a concentration of $0.151 \mathrm{~mol} / \mathrm{L}$. Instability of the association arises from the large interfacial tension between water and hexylamine, approximately $50 \mathrm{mN} / \mathrm{m}[10]$.

Accordingly, hexylamine's role appears to be not only in surface hydrophobization. We suggest that at high concentrations, this surfactant forms a hybrid organic-inorganic particle together with silica (Fig. 2) and the attachment of such hybrid particles at the decane/water interface promotes formation of oil droplets in the aqueous phase.

\section{Conclusion}

The amount of short-chain hexylamine required to form emulsions together with silica is large compared to the amount of long-chain surfactant. W/O emulsions were formed when the volume fraction of hexylamine exceeded that of the solid particles. It is assumed that at high concentrations, this surfactant and silica form hybrid organic-inorganic 'particle' which promotes the formation of oil droplets in water. 


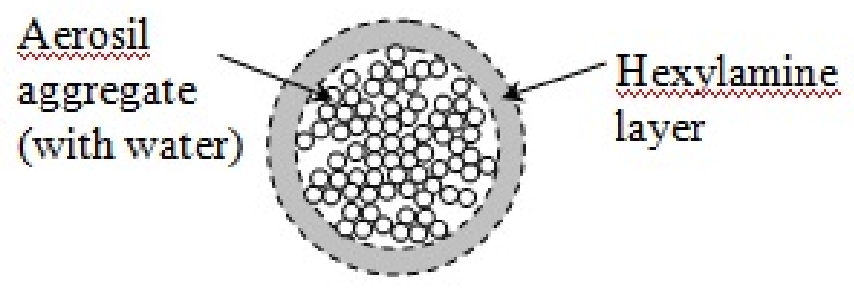

FIG. 2. Assumed scheme of hybrid particle formed in the ternary system silicahexylamine-water at high concentration of hexylamine

\section{References}

[1] Aveyard R., Binks B.P., Clint J. Emulsions stabilized by solely colloidal parti-cles. Adv. Colloid Interface Sci., 2003, 100-102, P. 503-546.

[2] Binks B.P., Murakami R. Phase inversion of particle-stabilized materials from foams to dry water. Nature Materials, 2006, 5, P. 865-869.

[3] Horozov T.S., Aveyard R., Clint J., Neumann B. Particle zips: vertical emul-sion films with particle monolayers at their surfaces. Langmuir, 2005, 21, P. 2330-2341.

[4] Yan N., Gray M.R., Masliyah J.H. On water-in-oil emulsions stabilized by fine solids. Colloids and Surfaces. A: Physicochem. Engineering Aspects, 2001, 193, P. 97-107.

[5] Abend S., Lagaly G. Bentonite and double hydroxides as emulsifying agents. Clay Minerals, 2001, 36, P. $557-570$.

[6] Tcholakova S., Denkov N.D., Lips A. Comparison of solid particles, globular proteins and surfactants as emulsifiers. Phys. Chem. Chem. Phys., 2008, 10 (12), P. 1608-1627.

[7] Kruglyakov P.M., Nushtaeva A.V. Emulsion stabilized by solid particles: in-fluence of the capillary pressure. In: Emulsions: Structure, Stability and Inter-actions, D.N. Petsev (Ed.). Elsevier, Amsterdam, 2004, P. 641676.

[8] Nushtaeva A.V., Shumkina A.V., Kruglyakov P.M., Elaneva S.I. Effect of Aqueous Phase Structuring on the Properties of Model Emulsion Films Stabi-lized with Solid. Colloid Journal, 2011, 73 (6), P. 821-829.

[9] Alargova R.G., Warhadpande D.S., Velev O.D., Paunov V.N. Foam superstabilization by polymer microrods. Langmuir, 2004, 20 (24), P. 10371-10374.

[10] Gonzenbach U.T., Studart R.R., Tervoort E., Gauker L.J. Ultrastable particle-stabilised foams. Angew. Chem. Int. Ed. Engl., 2006, 43, P. 3526-3530.

[11] Gonzenbach U.T., Studart R.R., Tervoort E., Gaukler L.J. Tailoring the mi-crostructure of particle-stabilized wet foams. Langmuir, 2007, 23, P. 1025-1032.

[12] Kruglyakov P.M., Elaneva S.I., Vilkova N.G. About mechanism of foam stabi-lization by solid particles. $A d v$. Colloid and Interface Sci., 2011, 165, P. 108-118.

[13] Vilkova N.G., Elaneva S.I., Karakashev S.I. The hexylamine concentration influence on the properties of the foams and foam films stabilized by Ludox. Mendeleev Commun., 2012, 22, P. 227-228.

[14] Dinsmore A.D., Hsu M.F., et al. Colloidosomes: selectively permeable capsules composed of colloidal particles. Science, 2002, 298, P. 1006-1009.

[15] Mao Zh., Xu H., Wang D. Molecular mimetric self-assembly of colloidal parti-cles. Advanced Functional Materials, 2010, 20 (7), P. 1053-1074.

[16] Simovic S., Heard P., Prestidge C.A. Hybrid lipid-silica microcapsules engi-neered by phase coacervation of Pickering emulsions to enhance lipid hydroly-sis. Phys. Chem. Chem. Phys., 2010, 12, P. 7162-7170.

[17] Wong C.H., Tervoort E., et al. Macroporous polymers from particle-stabilized foams. J. Ma-ter. Chem., 2009, 19, P. 5129-5133.

[18] Nushtaeva A.V., Shumkina A.V. Properties of emulsion and free emulsion (aqueous) films stabilized with hexylamine-modified silica. Colliod Journal, 2013, 75 (3), P. 326-332.

[19] Nushtaeva A.V. Stabilization of emulsions and emulsion films by silica with hexylamine. Mendeleev Commun., 2012, 22 (4), P. 225-226.

[20] Nushtaeva A.V. Contact angles of selective wetting of hexylamine-modified silica. Colloids and Surfaces A: Physicochem. Engineering Aspects, 2014, 451, P. 101-106.

[21] Nushtaeva A.V., Vilkova N.G., Mishina S.I. The effect of modifier concentration on the stability of emulsions and foams stabilized with colloidal silica particles. Colloid Journal, 2014, 76 (6), P. 717-724. 
[22] Stöber W., Fink A., Bohn E. Controlled growth of monodisperse silica spheres in the micron size range. $J$. Colloid Interface Sci., 1968, 26, P. 62-69.

[23] Grigorov O.N., Karpova I.F., et al. Guide to practical work on colloidal chemistry, Khimia, Moscow, 1964. [In Russian]

[24] Churaev N.V., Sobolev V.D. Physical chemistry of wetting phenomena. In: Colloid Stability: The role of surface forces, Part II, T.F. Tadros (Ed.), Wiley-VCH Verlag GmbH and Co. KGaA, Weinheim, Germany, 2007, P. 127-152.

[25] Iler R.K. The chemistry of silica: solubility, polymerization, colloid and surface properties, and biochemistry. Wiley-Interscience, 1979, 866 p.

[26] Tadros Th.F., Vincent B. Emulsion stability. In: Encyclopedia of Emulsion Technology. P. Becher (Ed.), Marcel Dekker, New York, 1983, P. 129-285. 